Instrumental Achievements

\title{
Crystal Structure of Bis(2-mercaptothiazoline)copper(I) Chloride, $\left[\mathrm{Cu}(\mathrm{mtz})_{2} \mathrm{Cl}\right]$
}

\author{
Masahiko Maekawa*, Susumu Kitagawa**†, Youichi Nozaka***, \\ Megumu MUNAKATA*** and Takayoshi KuRODA-SowA*** \\ * Research Institute for Science and Technology, Kinki University, \\ Kowakae, Higashi-Osaka 577, Japan \\ ** Department of Chemistry, Tokyo Metropolitan University, \\ Minami-Ohsawa, Hachiouji, Tokyo 192-03, Japan \\ *** Department of Chemistry, Kinki University, Kowakae, Higashi-Osaka 577, Japan
}

Since copper(I) favors a four-coordinate tetrahedral geometry, there has been a vast body of tetrahedral copper(I) complexes characterized crystallographically. ${ }^{1}$ This is because the tetrahedral form is stable in copper(I) chemistry. On the other hand, although trigonal copper(I) complexes are coordinately unsaturated and unpopular, they often exist as reaction intermediates. It is important to add new structures to trigonal copper(I) chemistry. This work considered trigonal $\mathrm{CuL}_{3}$ having a thione sulfur donor.

Colorless single crystals of $\left[\mathrm{Cu}(\mathrm{mtz})_{2} \mathrm{Cl}\right](\mathbf{1})$ were obtained from a mixture of $\mathrm{CuCl}(0.05 \mathrm{mmol})$ and $\mathrm{mtz}$ $(0.10 \mathrm{mmol})$ in $\mathrm{CH}_{3} \mathrm{CN}(10 \mathrm{ml})$. Diffraction data were collected on a Rigaku AFC-5R diffractometer with graphite-monochromated $\mathrm{Mo}-\mathrm{K}_{\boldsymbol{\alpha}}$ radiation $(\lambda=0.71069$ $\AA)$. The structure was solved by a direct method (MITHRIL) $^{2}$ and refined anisotropically for nonhydrogen atoms by full-matrix least-squares calculations. The positions of the hydrogen atoms were obtained from difference Fourier syntheses. All of the calculations were performed using a TEXSAN crystallographic software package. ${ }^{3}$

The structure of complex 1 is shown in Fig. 1. This molecule has a two-fold symmetry along the $\mathrm{Cu}(1)-\mathrm{Cl}(1)$ vector, which coincides with the crystallographic twofold axis along the $b$-axis. The $\mathrm{Cu}(1)$ atom is coordinated by $\mathrm{S}$ atoms and a $\mathrm{Cl}$ ion, having a trigonal planar geometry. The $\mathrm{mtz}$ ligand has two coordination forms due to its tautomerism. One is a neutral thione sulfur form; the other is an anionic thiolate sulfur form. The molecular structure shows that the $\mathrm{C}(1)-\mathrm{S}(1)$ distance is 1.693(4) $\AA$, thus indicating the thione form. The $\mathrm{Cu}(1)-\mathrm{S}(1)$ distance of $2.232(1) \AA$ falls within the distances $\left(2.206(2)-2.480(3) \AA\right.$ ) of $\mathrm{Cu}^{\mathrm{I}}$ complexes with the thione form..$^{4 a-h}$ The $\mathrm{Cu}(1)-\mathrm{Cl}(1)$ distance of $2.283(2) \AA$ is close to that $(2.260 \AA)$ of analogous $\mathrm{Cu}^{\mathrm{I}}$ complexes $\left[\mathrm{Cu}(2 \text {-thiouracil })_{2} \mathrm{Cl}\right] .^{5 a}$ The angles around the $\mathrm{Cu}(1)$ atom are nearly $120^{\circ}$ in the range $(109.1$ -

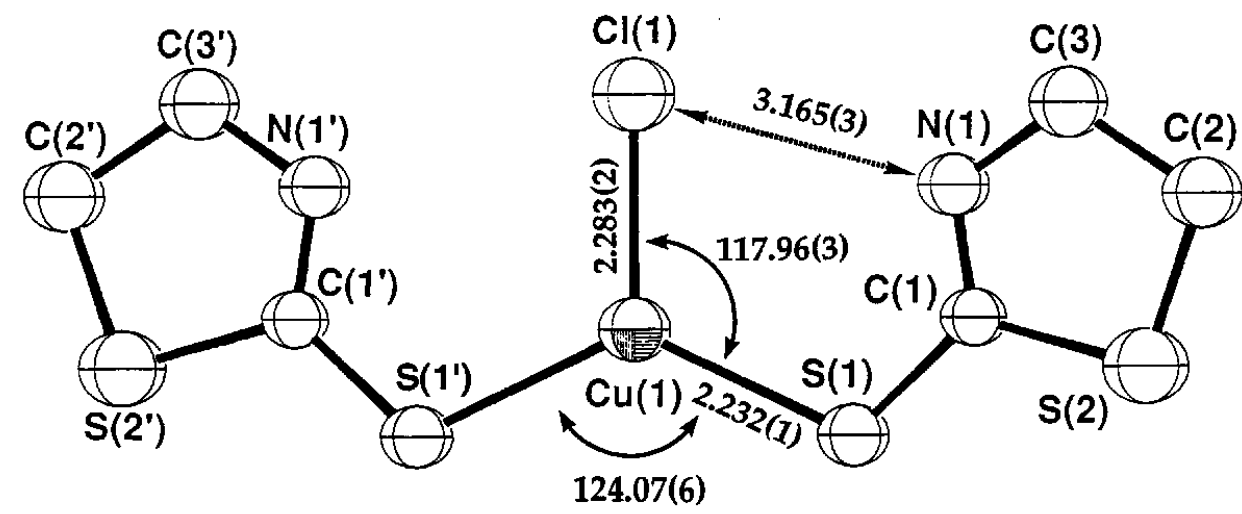

Fig. 1 ORTEP view of $\left[\mathrm{Cu}(\mathrm{mtz})_{2} \mathrm{Cl}\right](1)$ and atomic numbering. Selected bond $\operatorname{distances}(\AA)$ and bond angles $\left({ }^{\circ}\right) . \quad \mathrm{Cu}(1)-\mathrm{Cl}(1)=2.283(2), \mathrm{Cu}(1)-\mathrm{S}(1)=2.232(1)$, $\mathrm{C}(1)=\mathrm{S}(1)=1.693(4), \quad \mathrm{Cl}(1)-\mathrm{Cu}(1)-\mathrm{S}(1)=117.96(3), \quad \mathrm{S}(1)-\mathrm{Cu}(1)-\mathrm{S}\left(1^{\prime}\right)=$ 124.07(6).

\footnotetext{
$\dagger$ To whom correspondence should be addressed.
} 
Table 1 Crystal and experimental data

Formula: $\mathrm{CuClS}_{4} \mathrm{~N}_{2} \mathrm{C}_{6} \mathrm{H}_{10}$

Formula weight: 337.40

Crystal system: monoclinic

Space group: $C 2 / c \quad Z=4$

$a=14.245(4) \AA$

$b=6.342(2) \AA$

$c=13.519(2) \AA$

$\beta=101.01(1)^{\circ}$

$V=1178.7(5) \AA^{3}$

$D_{\text {calc }}=1.901 \mathrm{~g} / \mathrm{cm}^{3}$

$R=0.036 \quad R w=0.044$

No. of reflection used $=1536 \quad(I>3 \sigma(I))$

Measurement: Rigaku AFC-5R

Program system: TEXSAN

Structure determination: direct method (MITHRIL)

Refinement: full-matrix least-squares

Table 2 Final atomic coordinates and equivalent isotropic thermal parameters $B_{\text {eq }}\left(\AA^{2}\right)$ of non-hydrogen atoms

\begin{tabular}{lllll}
\hline \multicolumn{1}{c}{ Atom } & \multicolumn{1}{c}{$x$} & \multicolumn{1}{c}{$y$} & \multicolumn{1}{c}{$z$} & \multicolumn{1}{c}{$B_{\text {eq }}$} \\
\hline $\mathrm{Cu}(1)$ & 1.0000 & $0.0469(1)$ & 0.2500 & $3.18(3)$ \\
$\mathrm{Cl}(1)$ & 1.0000 & $0.4068(2)$ & 0.2500 & $4.11(6)$ \\
$\mathrm{S}(1)$ & $1.08696(7)$ & $-0.1181(1)$ & $0.38994(7)$ & $3.13(4)$ \\
$\mathrm{S}(2)$ & $1.1784(1)$ & $-0.0122(2)$ & $0.60728(8)$ & $4.56(5)$ \\
$\mathrm{N}(1)$ & $1.1092(2)$ & $0.2684(5)$ & $0.4758(2)$ & $3.0(1)$ \\
$\mathrm{C}(1)$ & $1.1209(2)$ & $0.0646(6)$ & $0.4838(3)$ & $2.6(1)$ \\
$\mathrm{C}(2)$ & $1.1932(3)$ & $0.2543(7)$ & $0.6535(3)$ & $3.9(2)$ \\
$\mathrm{C}(3)$ & $1.1393(3)$ & $0.3943(7)$ & $0.5676(3)$ & $3.8(2)$ \\
& & & &
\end{tabular}

$B_{\mathrm{eq}}=(4 / 3) \Sigma_{i} \Sigma_{j} \beta_{i j}\left(a_{i} \cdot a_{j}\right)$.

135.4 $\AA$ ) of $\mathrm{Cu}^{1}$ complexes $^{5 \mathrm{a}-\mathrm{f}}$ having a trigonal planar. geometry. In the intermolecule, the $\mathrm{N}-\mathrm{H}$ group of two mtz ligand has two hydrogen bonds between the $\mathrm{Cl}$ atom, whose $\mathrm{N}(1) \cdots \mathrm{Cl}(1)$ distance is $3.165(3) \AA$. This hydrogen-bond distance is similar to those (3.079$3.33 \AA$ ) of analogous $\mathrm{Cu}^{\mathrm{I}}$ complexes ${ }^{4 \mathrm{a}-\mathrm{c}}$ having a thioamide framework. This is associated with the stability of the trigonal structure.
This work was supported in part by a Grant-in-Aid for Science Research (No. 04453049, 05453131 and 05453046) from the Ministry of Education, Science and Culture in Japan.

\section{References}

1. B. J. Hathaway, "Comprehensive Coordination Chemistry", ed. G. Wilkinson, Chap. 53, p. 553, Pergamon Press, Oxford, 1987.

2. "MITHRIL", J. Gilmore, J. Appl. Cryst., 17, 42; Univ. of Glasgow, Scotland, UK (1984).

3. "TEXSAN", TEXRAY Structure Analysis Package, Molecular Structure Corporation, The Woodlands, TX, USA (1985).

4. (a) E. W. Ainscough, A. M. Brodie, J. M. Husbands, G. J. Gainsford, E. J. Gabe and N. F. Curtis, J. Chem. Soc., Dalton Trans., 1985, 151. (b) T.S. Lobana, P. K. Bhatia and E. R. Tiekink, J. Chem. Soc., Dalton Trans., 1989, 749. (c) P. Karagiannidis, S. K. Hadjikakou, P. Aslanidis and A. Hountas, Inorg. Chim. Acta, 178, 27 (1990). (d) E. S. Raper, J. R. Creighton, J. D. Wilson, W. Clegg and A. Milne, Inorg. Chim. Acta, 155, 85 (1989). (e) S. C. Kokkou, S. Fortier and P. J. Rentzeperis, Acta Crystallogr., C39, 178 (1983). (f) S. C. Kokkou and V. Schramm, Acta Crystallogr., C41, 1040 (1985). (g) P. Karagiannidis, P. Aslanidis, S. Papastefanou, D. Mentzafos, A. Hountas and A. Terzis, Polyhedron, 9, 2833 (1990). (h) P. Karagiannidis, P. Aslanidis, S. Papastefaunou, D. Mentzafous, A. Hountas and A. Terzis, Inorg. Chim. Acta, 156, 265 (1989).

5. (a) G. W. Hunt and E. L. Amma, J. Chem. Soc., Chem. Commun., 1973, 869. (b) D. Coucouvanis, C. N. Murphy and S. K. Kanodia, Inorg. Chem., 19, 2993 (1980). (c) P. G. Eller and P. W. R. Corfield, J. Chem. Soc., Chem. Commun., 1971, 105. (d) M.S. Weininger, G. W. Hunt and E. L. Amma, J. Chem. Soc., Chem. Commun., 1972, 1140. (e) E. W. Ainscough, A. M. Brodie and K. L. Brown, J. Chem. Soc., Dalton Trans., 1980, 1042. (f) E. R. Atkinson, D. J. Gardiner, A. R. W. Jackson and F. S. Raper, Inorg. Chim. Acta, 98, 35 (1985).

(Received August 9, 1993) (Accepted August 26, 1993) 